\title{
A fuzzy quality function deployment approach to improve a component of a supervisory control and data acquisition system
}

\author{
Ciprian Cristea $^{{ }^{*}}$, Ciprian Saşa $^{2}$, Maria Cristea $^{3}$ \\ ${ }^{1}$ Technical University of Cluj-Napoca, Faculty of Electrical Engineering, ciprian.cristea@emd.utcluj.ro, Romania \\ ${ }^{2}$ Technical University of Cluj-Napoca, Faculty of Electrical Engineering, sasa ciprian@yahoo.com, Romania \\ ${ }^{3}$ Technical University of Cluj-Napoca, Faculty of Electrical Engineering, fagarasan maria@yahoo.com, Romania
}

\begin{abstract}
Monitoring and control of electric transformer stations, frequently spread out over small or large geographical areas, are achieved with supervisory control and data acquisition (SCADA). Quality function deployment (QFD) is a valuable analyzing tool in product design and development. To solve the uncertainty or inherent imprecision in QFD, many researchers have applied the fuzzy set theory to QFD and have developed various fuzzy QFD approaches. The literature regarding applying fuzzy QFD for analyzing subsystems of SCADA, to the best of our knowledge, remains inexistent. In this paper, a fuzzy QFD approach is used to effectively determine the design requirements of a SCADA component.
\end{abstract}

\section{Introduction}

The SCADA (supervisory control and data acquisition) systems play a vital role in modern power generation systems. In the SCADA networks, data acquisition systems, data transmission systems and Human Machine Interface (HMI) software are integrated for providing the centralized monitoring and control system for processing outputs and inputs A. Rezai, P. Keshavarzi, Z. Moravej [1]. SCADA system monitors the status of different equipments in substation and accordingly sends control signals to the remote control equipments. Historical data of the substation are collected and alarms in the event of electrical accidents or faults are generated. Thus, substations rely on SCADA for remote supervision and control, improving the reliability of the network and minimizing the downtime, their proper functioning is vital to modern society.

The rapidly increasing globalization of economic environment has decreased the life cycles of products. Companies have to develop new products that meet customer requirements in a shorter time to improve their competitive advantage. Companies realize the importance of effectively translating customer requirements into engineering characteristics and quality factors that should be considered in product design and development H.-T. Liu [2], C.C. Otel [3], I.A. Iancu [4], C.E Stoenoiu [5].
There are various product design and development approaches that have been developed and applied in several areas. QFD (quality function deployment) is a useful method for quality planning, continuous product improvement and decision making which translates the customer requirements into design or engineering characteristics that are taken into account in product design and then into specific plans and production requirements, associated to its manufacturing processes C.K.M. Lee, C.T.Y. Ru, C.L. Yeung, K.L. Choy, W.H. Ip [6].

Traditional QFD is based on communication with customers and market survey to acquire customer requirements and effectively decrease product development time. In order to set different parameters, linguistic variables have to be used by product developers. Mostly, the result of market survey and linguistic variables used are imprecise or uncertain, usually resulting in biased analysis results. In order to cope with this problem, a number of scholars have applied the fuzzy set theory to QFD and developed various fuzzy QFD approaches H.-T. Liu [2]. The approaches contain conventional QFD computation using fuzzy variables E. Bottani, A. Rizzi [7], fuzzy tendency analysis X.X. Shen, X. Min, K.C. Tan [8], fuzzy MCDM (multicriteria decision making) Y.S. Sohn, I.S. Choi [9], fuzzy integral C.Y. Tsai [10], fuzzy analytical network process C. Kahraman, T. Ertay, G. Buyukozkan [11], fuzzy expected value Y. Chen, R.Y.K. Fung, J. Tang [12], fuzzy goal programming L.S. Chen, M.C. Weng [13], fuzzy expert systems C.K. Kwong, Y. Chen, H. Bai, D.S.K. Chan [14], etc.

QFD is composed of four successive matrices each

\footnotetext{
*Corresponding author: ciprian.cristea@emd.utcluj.ro
} 
corresponding to a stage of the product development cycle. These are product planning, part deployment, process planning, and production planning matrices, respectively. Customer requirements are translated into design characteristics by product planning matrix; important design characteristics are translated into product/part characteristics by the part deployment matrix; important product/part characteristics are translated into manufacturing operations by the process planning matrix; important manufacturing operations are translated into day-to-day operations and controls by the production planning matrix M. Dursun, E. E. Karsak [15]. Here, the current paper concentrates on the first matrix (customer planning matrix), that is also called the "House of Quality (HOQ)". HOQ show the relationship between customer requirements (what to do) and engineering characteristics (how to do it). It represents the engine that drives the entire QFD process, most QFD researches focusing only on this stage. The main aim of this paper is to propose a fuzzy QFD approach to support the decision making process in improving a component of a SCADA system.

The remainder of the paper is organized as follows. In the next paragraph, the fuzzy QFD approach methodology is described. In the third section, a case study is discussed with the results and, finally, the last section summarizes the conclusions.

\section{Methodology}

The major steps D.H. Akbas, B. Bilgen [16], F. R. Lima-Junior, L. C. R. Carpinetti [17] of conducting fuzzy QFD approach to analyze the component of a SCADA system requirement are described below.

1) Identify customer requirements - represent the initial input for the HOQ and point out those product specifications that should be took into account.

2) Determine the importance of customer requirements usually, customer requirements are of different degrees of importance. A fuzzy set represents a class of objects with a continuum of grades of membership ranging between zero and one L.A. Zadeh [18]. If the value assigned is one, then the element belongs completely to the set and if the assigned value is zero, the element does not belong to the set G. Buyukozkan, A.G. Ciftci [19]. Finally, the value between 0 and 1 belongs to the fuzzy set only partially. A triangular fuzzy number (TFN) is represented with three points as follows. $\widetilde{M}=(l, m, u)$, where the parameters $l$, $m, u$, respectively, point out the smallest possible value, the most promising value, and the largest possible value that describe a fuzzy event A.R. Ghazikalayeh, M. Amirafshari, H.M. Mkrchyan, M. Taji [20]. In this paper, the linguistic variables are represented by TFN. The membership function of a TFN is given by (1) DH. Akbas, B. Bilgen [16].

$$
\boldsymbol{\mu}_{\widetilde{\mathbf{M}}}(\mathbf{x})=\left\{\begin{array}{l}
\frac{\mathbf{x}-\mathbf{l}}{\mathbf{m}-\mathbf{l}}, \mathbf{l} \leq \mathbf{x} \leq \mathbf{m} \\
\frac{\mathbf{u}-\mathbf{x}}{\mathbf{u}-\mathbf{m}}, \mathbf{m} \leq \mathbf{x} \leq \mathbf{u} \\
\text { 0, otherwise }
\end{array}\right.
$$

Table 1. Linguistic terms and corresponding fuzzy numbers on satisfaction value D.H. Akbas, B. Bilgen [16]

\begin{tabular}{|cc|}
\hline Linguistic term & Fuzzy number \\
\hline Very low $(\mathrm{VL})$ & $(1,1,2)$ \\
Low $(\mathrm{L})$ & $(1,2,3)$ \\
Medium $(\mathrm{M})$ & $(2,3,4)$ \\
\hline High $(\mathrm{H})$ & $(3,4,5)$ \\
\hline Very high $(\mathrm{VH})$ & $(4,5,5)$ \\
\hline
\end{tabular}

The linguistic variables of importance ratings are listed in Table 1.

In this study, fuzzy numbers are applied to model the linguistic judgments of the decision makers. The degree of importance of a customer requirement can be evaluated using the linguistic terms very low, low, medium, high and very high. The aggregated judgments of the $t$ decision makers $(d=1,2, \ldots, t)$, concerning the $i^{t h}$ customer requirement $(i=1,2, \ldots, n)$, are represented by $\tilde{x}_{i}$, given by (2) F.R. Lima-Junior, L.C.R. Carpinetti [17].

$$
\widetilde{\mathbf{x}}_{\mathbf{i}}=\frac{\sum_{\mathbf{d}=1}^{\mathbf{t}} \widetilde{\mathbf{x}}_{\mathbf{i}}^{\mathbf{d}}}{\mathbf{t}}
$$

where:

$\tilde{x}_{i}^{d}$ - the fuzzy number corresponding to the linguistic judgment oft the $i^{\text {th }}$ requirement, made by the $d^{\text {th }}$ decision maker;

After aggregation of the decision makers' judgments, the absolute weight $x_{i}$ is calculated by defuzzification, according to (3) F.R. Lima-Junior, L.C.R. Carpinetti [17].

$$
\mathbf{x}_{\mathbf{i}}=\frac{\mathbf{l}_{\widetilde{\mathbf{x}}_{\mathbf{i}}}+\mathbf{2} \cdot \mathbf{m}_{\widetilde{\mathbf{x}}_{\mathbf{i}}}+\mathbf{u}_{\widetilde{\mathbf{x}}_{\mathbf{i}}}}{4}
$$

The value of the absolute weight $x_{i}$ is then converted to the relative weight $w r_{i}$ according to (4) F.R. LimaJunior, L.C.R. Carpinetti [17].

$$
w r_{i}=\frac{x_{i}}{\sum_{i=1}^{n} x_{i}}
$$

3) Identify competitors and perform a competitive analysis - in order to improve its competitiveness in the market, the team has to assess the current performance of the company's product as well as its competitors' for each customer requirements.

4) Identify engineering characteristics - for capturing the customer requirements in technical terms.

5) Determine the relationships between engineering characteristics and customer requirements - the

\footnotetext{
"Corresponding author: ciprian.cristea@emd.utcluj.ro
} 
relationship matrix shows how engineering characteristics affects each customer requirement. The linguistic variables are used to indicate these relationships, as indicated in table 2.

Table 2. Linguistic terms indicating the relationship between engineering characteristics and customer requirements a.r. ghazikalayeh, m. Amirafshari, h.m. mkrchyan, m. Taji [20]

\begin{tabular}{cc}
\hline Linguistic term & Fuzzy number \\
\hline No relationship (NR) & $(0,0,0)$ \\
Weak (W) & $(1,1,3)$ \\
Average (A) & $(1,3,5)$ \\
\hline Strong (S) & $(5,9,9)$ \\
\hline
\end{tabular}

The aggregated judgments of the $t$ decision makers $(d$ $=1,2, \ldots, t)$, concerning the relationship between the $i^{t h}$ requirement $(i=1,2, \ldots, n)$ and the $j^{\text {th }}$ characteristic $(j=$ $1,2, \ldots, m)$, represented by $\tilde{u}_{i j}$, is given by (5) F.R. Lima-Junior, L.C.R. Carpinetti [17].

$$
\widetilde{\mathbf{u}}_{\mathrm{ij}}=\frac{\sum_{\mathbf{d}=1}^{\mathrm{t}} \widetilde{\mathbf{u}}_{\mathrm{ij}}^{\mathbf{d}}}{\mathbf{t}}
$$

where:

$\tilde{u}_{i j}^{d}$ judgment of the relationship between the $i^{\text {th }}$ requirement and $j^{\text {th }}$ characteristic, made by the $d^{\text {th }}$ decision maker;

The absolute weight of the $j^{\text {th }}$ criterion, $\widetilde{w}_{j}$, is computed as in (6) F.R. Lima-Junior, L.C.R. Carpinetti [17].

$$
\widetilde{\mathbf{w}}_{\mathbf{j}}=\sum_{\mathbf{i}=1}^{\mathrm{n}} \widetilde{\mathbf{u}}_{\mathbf{i j}} \times \mathbf{w} \mathbf{r}_{\mathbf{i}}
$$

where:

$w r_{i}$ - the value of relative weight of the $i^{\text {th }}$ customer requirement;

The absolute weight of each characteristic is defuzzified as in (7) and converted to the relative weight $w c_{j}$ according to (8) F.R. Lima-Junior, L.C.R. Carpinetti [17].

$$
\begin{aligned}
& \mathbf{w}_{\mathbf{j}}=\frac{\mathbf{l}_{\widetilde{\mathbf{w}}_{\mathbf{i}}}+\mathbf{2} \cdot \mathbf{m}_{\widetilde{\mathbf{w}}_{\mathbf{i}}}+\mathbf{u}_{\widetilde{\mathbf{x}}_{\mathbf{i}}}}{4} \\
& \mathbf{w c}_{\mathbf{j}}=\frac{\mathbf{w}_{\mathbf{j}}}{\sum_{\mathbf{j}=1}^{\mathbf{m}} \mathbf{w}_{\mathbf{j}}}
\end{aligned}
$$

6) Determine the ratings of engineering characteristics - the engineering characteristics with higher ratings are more important for the company's product to be successful in the market.

7) Perform a technical competitive analysis - the team has to assess the current performance of the company's product and its competitors' for each engineering characteristics.

\section{Case study}

In order to illustrate the implementation of the fuzzy QFD to support the decision making process in improving a subsystem of a SCADA system, a case study conducted in collaboration with the management of Romanian transmission and system operator (referred to as A company) is presented. The electrical substations are the key element for transmission and distribution of electrical energy. Designing the SCADA system for an electrical substation can be a difficult task, but has become an indispensable tool for power dispatching. Due to the fact that QFD can effectively collect customer requirements, support in product development, and enhance product quality, thus this study apply the fuzzy QFD approach in the process of designing a subsystem (central substation management unit) of a SCADA system.

The assessment was performed by five SCADA experts. In order to identify the customer requirements, the decision makers were interviewed. The customer requirements are the following: continuous availability $\left(\mathrm{CR}_{1}\right)$, data concentrator $\left(\mathrm{CR}_{2}\right)$, protocol converter $\left(\mathrm{CR}_{3}\right)$, communication server $\left(\mathrm{CR}_{4}\right)$, synchronization with all equipment's time $\left(\mathrm{CR}_{5}\right)$, communication security and access control $\left(\mathrm{CR}_{6}\right)$, hot standby redundant configuration $\left(\mathrm{CR}_{7}\right)$, real-time data processing $\left(\mathrm{CR}_{8}\right)$, no moving parts $\left(\mathrm{CR}_{9}\right)$, redundant power supply $\left(\mathrm{CR}_{10}\right)$ and real-time database $\left(\mathrm{CR}_{11}\right)$. These specialists $\left(\mathrm{EX}_{1}, \ldots\right.$ $\mathrm{EX}_{5}$ ) were responsible for providing the linguistic judgments required for assessing the degree of importance

\begin{tabular}{|c|c|c|c|c|c|c|c|}
\hline $\begin{array}{l}\text { Cistomer } \\
\text { requirements }\end{array}$ & $\mathrm{EX}_{1}$ & $\mathrm{EX}_{2}$ & $\mathbf{E X}_{3}$ & $\mathbf{E X}_{4}$ & $\mathbf{E X}_{5}$ & $\begin{array}{l}\text { Average } \\
\text { fuzzy } \\
\text { number }\end{array}$ & $\begin{array}{l}\text { Rehalive } \\
\text { weight }\end{array}$ \\
\hline $\mathrm{CR}_{1}$ & $(4,5,5)$ & $(4,5,5)$ & $(4,5,5)$ & $(4,5,5)$ & $(4,5,5)$ & $(4,5,5)$ & 0.11 \\
\hline $\mathbf{C R}_{2}$ & $(3,4,5)$ & $(3,4,5)$ & $(23,4)$ & $(3,4,5)$ & $(23,4)$ & $(2.63 .6,4.6)$ & 0.08 \\
\hline $\mathrm{CR}_{3}$ & $(23,4)$ & $(23,4)$ & $(3,4,5)$ & $(3,4,5)$ & $(3,4,5)$ & $(2,63.6,4.6)$ & 0.08 \\
\hline $\mathbf{C R}_{4}$ & $(3,4,5)$ & $(3,4,5)$ & $(3,4,5)$ & $(3,4,5)$ & $(23,4)$ & $(2.8,3.8,4.8)$ & 0.08 \\
\hline $\mathbf{C R}_{5}$ & $(23,4)$ & $(3,4,5)$ & $(3,4,5)$ & $(3,4,5)$ & $(3,4,5)$ & $(2,8,3.8,4.8)$ & 0.08 \\
\hline $\mathbf{C R}_{6}$ & $(4,5,5)$ & $(4,5,5)$ & $(3,4,5)$ & $(4,5,5)$ & $(4,5,5)$ & $(3,8,4.8,5)$ & 0.1 \\
\hline $\mathbf{C R}_{7}$ & $(4,5,5)$ & $(4,5,5)$ & $(4,5,5)$ & $(4,5,5)$ & $(4,5,5)$ & $(4,5,5)$ & 0.11 \\
\hline $\mathbf{C R}_{8}$ & $(23,4)$ & $(3,4,5)$ & $(23,4)$ & $(3,4,5)$ & $(3,4,5)$ & $(2.63 .6,4.6)$ & 0.08 \\
\hline $\mathrm{CR}_{9}$ & $(4,5,5)$ & $(3,4,5)$ & $(4,5,5)$ & $(4,5,5)$ & $(4,5,5)$ & $(3,8,8,8,8,5)$ & 0.1 \\
\hline $\mathrm{CR}_{10}$ & $(4,5,5)$ & $(4,5,5)$ & $(4,5,5)$ & $(4,5,5)$ & $(4,5,5)$ & $(4,5,5)$ & 0.11 \\
\hline$\overline{C \mathrm{CR}_{11}}$ & $(2,3,4)$ & $(3,4,5)$ & $(2,3,4)$ & $(3,4,5)$ & $(2,3,4)$ & $(24,34,44)$ & 0.07 \\
\hline
\end{tabular}
of the customer requirements. The results in the weights of customer requirements are shown in Table III.

Table 3. Weights of customer requirements

In the next stage, a competitive analysis was performed. Company A's ability to meet customer requirements on a scale of 1 to 5 ( 1 worst -5 best) was ranked. This case study deals with four competitors, denoted B, C, D and E company. The competitive analysis is shown in fig. 1 . It can be noticed that $\mathrm{A}$ company has to improve data parameter. 


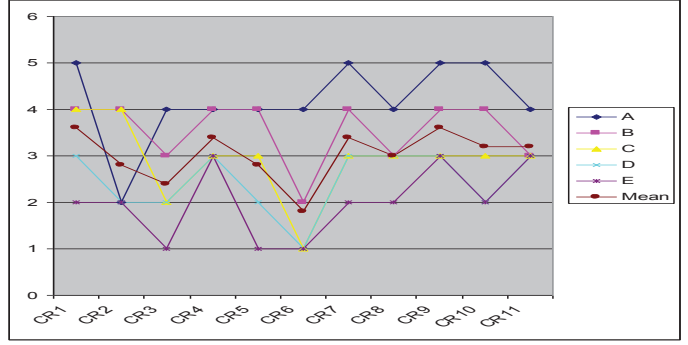

Fig. 1. Competitive analysis for customer requirements

In the next step, the decision makers agreed the following list of engineering characteristics: warm standby power supply $\left(\mathrm{EC}_{1}\right)$, data acquisition from the substation control systems, protection, automation service equipments $\left(\mathrm{EC}_{2}\right)$, communication system $\left(\mathrm{EC}_{3}\right)$, independent and redundant communication ports $\left(\mathrm{EC}_{4}\right)$, GPS time servers $\left(\mathrm{EC}_{5}\right)$, secure database connection $\left(\mathrm{EC}_{6}\right)$, hot standby system $\left(\mathrm{EC}_{7}\right)$, time stamping application $\left(\mathrm{EC}_{8}\right)$, modular construction $\left(\mathrm{EC}_{9}\right)$, hot-swap enabled power supplies $\left(\mathrm{EC}_{10}\right)$ and Random Access Memory $\left(\mathrm{EC}_{11}\right)$.

Table 4. Fuzzy number of the aggregated degrees of relationship and values of the relative weights of the engineering characteristics

\begin{tabular}{|c|c|c|c|c|c|}
\hline & $\mathrm{EC}_{1}$ & $\mathrm{EC}_{2}$ & $\mathrm{EC}_{3}$ & $\mathrm{EC}_{4}$ & $\mathrm{EC}_{5}$ \\
\hline $\mathrm{CR}_{1}$ & $(5,9,9)$ & $(0,0,0)$ & $(0,0,0)$ & $(0,0,0)$ & $(0,0,0)$ \\
\hline $\mathrm{CR}_{2}$ & $(0,0,0)$ & $(3.4,6.6,7.4)$ & $(1,2.6,4.0)$ & $(1,3,5)$ & $(0,0,0)$ \\
\hline $\mathrm{CR}_{3}$ & $(0,0,0)$ & $(0,0,0)$ & $(3.4,6.6,7.4)$ & $(0.8,0.8,2.4)$ & $(0,0,0)$ \\
\hline $\mathrm{CR}_{4}$ & $(0,0,0)$ & $(1,22,2)$ & $(0,0,0)$ & $(4.2,7.8,8.2)$ & $(0,0,0)$ \\
\hline $\mathrm{CR}_{5}$ & $(0,0,0)$ & $(1,1,3)$ & $(0,0,0)$ & $(0,0,0)$ & $(4.2,7.8,8.2)$ \\
\hline $\mathrm{CR}_{6}$ & $(0,0,0)$ & $(0,0,0)$ & $(0,0,0)$ & $(0,0,0)$ & $(0,0,0)$ \\
\hline $\mathrm{CR}_{7}$ & $(5,9,9)$ & $(0,0,0)$ & $(0,0,0)$ & $(0,0,0)$ & $(0,0,0)$ \\
\hline $\mathrm{CR}_{8}$ & $(0,0,0)$ & $(1,2.64 .0)$ & $(1,1,3)$ & $(0,0,0)$ & $(4.2,7.8,8.2)$ \\
\hline $\mathrm{CR}_{9}$ & $(1,1.8,3.8)$ & $(0,0,0)$ & $(0,0,0)$ & $(0,0,0)$ & $(0,0,0)$ \\
\hline $\mathrm{CR}_{10}$ & $(5,9,9)$ & $(0,0,0)$ & $(0,0,0)$ & $(0,0,0)$ & $(0,0,0)$ \\
\hline $\mathrm{CR}_{11}$ & $(0,0,0)$ & $(3.4,6.6,7.4)$ & $(0,0,0)$ & $(0,0,0)$ & $(1,2.6,4.6)$ \\
\hline $\begin{array}{c}\text { Relative } \\
\text { weight }\end{array}$ & 0.1619 & 0.1074 & 0.0592 & 0.0788 & 0.0676 \\
\hline
\end{tabular}

\begin{tabular}{|c|c|c|c|c|c|c|}
\hline & $\mathrm{EC}_{6}$ & $\mathrm{EC}_{7}$ & $\mathrm{EC}_{8}$ & $\mathrm{EC}_{9}$ & $\mathrm{EC}_{10}$ & $\mathrm{EC}_{11}$ \\
\hline $\mathrm{CR}_{1}$ & $(0,0,0)$ & $\begin{array}{c}(42,4,6,6,8 . \\
2)\end{array}$ & $(0,0,0)$ & $(1,2,6,4.6)$ & $(5,9,9)$ & $(0,0,0)$ \\
\hline $\mathrm{CR}_{2}$ & $\begin{array}{c}(0.8,0.8,2 . \\
4)\end{array}$ & $(0,0,0)$ & $(1,3,5)$ & $(0,0,0)$ & $(0,0,0)$ & $(1,3,5)$ \\
\hline $\mathrm{CR}_{3}$ & $(0,0,0)$ & $(0,0,0)$ & $(0,0,0)$ & $\begin{array}{l}(0,0,0) \\
\end{array}$ & $(0,0,0)$ & $(0,0,0)$ \\
\hline $\mathrm{CR}_{4}$ & $(0,0,0)$ & $(0,0,0)$ & $(1,2,6,4.6)$ & $(0,0,0)$ & $(0,0,0)$ & $(1,1,3)$ \\
\hline $\mathrm{CR}_{5}$ & $(0,0,0)$ & $(0,0,0)$ & $(0,0,0)$ & $(0,0,0)$ & $(0,0,0)$ & $(0,0,0)$ \\
\hline $\mathrm{CR}_{6}$ & $\begin{array}{c}(42,4,6,8.8 . \\
2)\end{array}$ & $(0,0,0)$ & $(0,0,0)$ & $(0,0,0)$ & $(1,3,5)$ & $(0,0,0)$ \\
\hline $\mathrm{CR}_{7}$ & $(1,2.6,4.6)$ & $\begin{array}{c}(4,2,4.6,8.8 . \\
2)\end{array}$ & $(0,0,0)$ & $(1,2,6,4.6)$ & $\begin{array}{c}(4,2,4.6,8.8 . \\
2)\end{array}$ & $(0,0,0)$ \\
\hline $\mathrm{CR}_{8}$ & $\begin{array}{c}(0.8,0.8,2 . \\
4)\end{array}$ & $(0,0,0)$ & $(5,9,9)$ & $(0,0,0)$ & $(0,0,0)$ & $\begin{array}{c}(1,2,2,4 . \\
2)\end{array}$ \\
\hline $\mathrm{CR}_{9}$ & $(0,0,0)$ & $(0,0,0)$ & $\begin{array}{c}(0.8,0.8,2.2 . \\
4)\end{array}$ & $\begin{array}{c}(4,2,4,6,8.8 \\
2)\end{array}$ & $(1,2,2,4,2)$ & $(0,0,0)$ \\
\hline $\mathrm{CR}_{10}$ & $(0,0,0)$ & $(1,2.6,4.6)$ & $(0,0,0)$ & $(1,3,5)$ & $\begin{array}{c}(4,2,4.6,8.8 . \\
2)\end{array}$ & $(0,0,0)$ \\
\hline $\mathrm{CR}_{11}$ & $\begin{array}{c}(0.8,0.8,2 . \\
4)\end{array}$ & $(0,0,0)$ & $(1,3,5)$ & $(0,0,0)$ & $(0,0,0)$ & $(5,9,9)$ \\
\hline $\begin{array}{l}\text { Relati } \\
\text { ve } \\
\text { weight }\end{array}$ & 0.0657 & 0.0727 & 0.0695 & 0.0981 & 0.1493 & 0.0697 \\
\hline
\end{tabular}

Table IV presents these results regarding the degrees of relationship between the customer requirements and engineering characteristics, based on the linguistic terms and the relative weight.

In the final stage, a competitive analysis was performed. Company A's ability to meet engineering characteristics on a scale of 1 to 5 ( 1 worst -5 best) was ranked and then was compared to competitors. The competitive analysis is illustrated in fig. 2.

It can be noticed that A company has to improve the independent and redundant communication ports and the time stamping application.

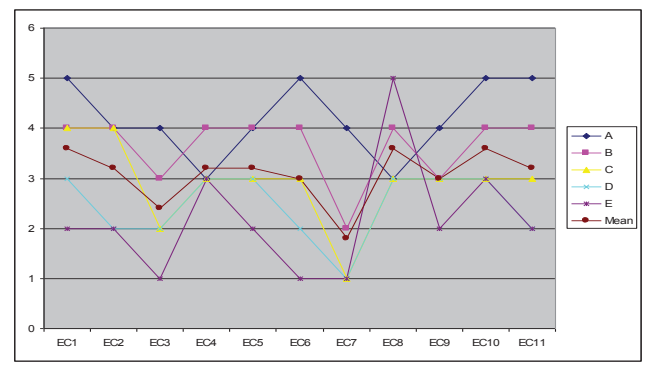

Fig. 2. Competitive analysis for engineering characteristics

\section{CONCLUSIONS}

SCADA systems have many advantages, such as handling a large amount of data required to monitor the electrical state of all power lines, equipments and can help in a short period of time diagnose the failure state of the system. This paper presented a fuzzy QFD approach to support the decision making process in improving a subsystem of a SCADA system. By integrating fuzzy set theory, this approach is also capable to capture the vagueness and subjectivity in expert's assessment and to streamline the analysis of QFD information. The results reveal that the fuzzy QFD approach may be a very useful tool to support decision makers to perform HOQ analysis without difficulties.

\section{REFERENCES}

[1] A. Rezai, P. Keshavarzi, Z. Moravej, "Key management issue in SCADA networks: A review”, JESTECH, 20, pp. 354-363, 2017.

[2] H.-T. Liu, "Product design and selection using fuzzy QFD and fuzzy MCDM approaches", Appl. Math. Model., 35, pp. 482-496, 2011.

[3] C.C. Otel, "Conceptul de calitate", Revista de Management şi Inginerie Economică, 5,(18), pp.199-200, 2006.

[4] I.A. Iancu, "Marketing Mix in Financial Investment Services Companies", SEA-Practical Application on Science, IV(10), pp. 59-64, 2016.

[5] C.E Stoenoiu, "Economic and financial analysis of a company-support for users of information", J. Int. Sci. Publ. : Econ. Bus., 6(3), pp. 333-347, 2012.

[6] C.K.M. Lee, C.T.Y. Ru, C.L. Yeung, K.L. Choy, W.H. Ip "Analyze the healthcare service requirement using fuzzy QFD", Comput. Ind., 74, pp. 1-15, 2015.

[7] E. Bottani, A. Rizzi, "Strategic management of logistics service: a fuzzy QFD approach", Int. J. Prod. Econ., 103, pp. 585-599, 2006.

[8] X.X. Shen, X. Min, K.C. Tan, "Listening to the future voice of the customer using fuzzy trend analysis in quality function deployment", Qual. Eng., 13, pp. 419-425, 2001.

[9] Y.S. Sohn, I.S. Choi, "Fuzzy QFD for supply chain management with reliability", Reliab. Eng. Syst. Safe., 72, pp. 327-334, 2001.

[10] C.Y. Tsai, "Using fuzzy QFD to enhance manufacturing strategic planning”, J. Chin. Inst. Ind. Eng., 18, pp. 33-41, 2003.

[11] C. Kahraman, T. Ertay, G. Buyukozkan, "A fuzzy optimization model for QFD planning process using analytic network approach", Eur. J. Oper. Res., 171, pp. 390-411, 2006. 
[12] Y. Chen, R.Y.K. Fung, J. Tang, "Rating technical attributes in fuzzy QFD by integrating fuzzy weighted average method and fuzzy expected value operator", Eur. J. Oper. Res., 174, pp. 1553-1566, 2006

[13] L.S. Chen, M.C. Weng, "An evaluation approach to engineering design in QFD processes using fuzzy goal programming models", Eur. J. Oper. Res., 172, pp. 230-248, 2006.

[14] C.K. Kwong, Y. Chen, H. Bai, D.S.K. Chan, "A methodology of determining aggregated importance of engineering characteristics in QFD”, Comput. Ind. Eng., 53, pp. 667-679, 2007.

[15] M. Dursun, E. E. Karsak, “A QFD-based fuzzy MCDM approach for supplier selection”, Appl. Math. Model., 37, pp. 5864-5875, 2013.
[16] D.H. Akbas, B. Bilgen, "An integrated fuzzy QFD and TOPSIS methodology for choosing the ideal gas fuel at WWTPs", Energy, 125, pp. 484-497, 2017

[17] F.R. Lima-Junior, L.C.R. Carpinetti, "A multicriteria approach based on fuzzy QFD for choosing criteria for supplier selection", Comput. Ind. Eng., 101, pp. 269-285, 2016.

[18] L.A. Zadeh, "Fuzzy sets", Inf. Control, 8, pp. 338-353, 1965.

[19] G. Buyukozkan, A.G. Ciftci, "Combined fuzzy AHP and fuzzy TOPSIS based strategic analysis of electronic service quality in healthcare industry", Expert. Syst. Appl., 39(3), pp. 2341-2354, 2012.

[20] A.R. Ghazikalayeh, M. Amirafshari, H.M. Mkrchyan, M. Taji, "Application of fuzzy hybrid analytic network process in equipment selection of open-pit metal mines, Int. J. Res. Ind. Eng., 2(3), pp. 35-46, 2013. 